\title{
Migraine headaches in Chronic Fatigue Syndrome (CFS): Comparison of two prospective cross- sectional studies
}

\author{
Murugan K Ravindran, Yin Zheng, Christian Timbol, Samantha J Merck, James N Baraniuk
}

\begin{abstract}
Background: Headaches are more frequent in Chronic Fatigue Syndrome (CFS) than healthy control (HC) subjects. The 2004 International Headache Society (IHS) criteria were used to define CFS headache phenotypes.

Methods: Subjects in Cohort 1 ( $H C=368 ; C F S=203$ ) completed questionnaires about many diverse symptoms by giving nominal (yes/no) answers. Cohort 2 ( $\mathrm{HC}=21$; CFS $=67$ ) had more focused evaluations. They scored symptom severities on 0 to 4 anchored ordinal scales, and had structured headache evaluations. All subjects had history and physical examinations; assessments for exclusion criteria; questionnaires about CFS related symptoms (0 to 4 scale), Multidimensional Fatigue Inventory (MFI) and Medical Outcome Survey Short Form 36 (MOS SF-36).

Results: Demographics, trends for the number of diffuse "functional" symptoms present, and severity of CFS case designation criteria symptoms were equivalent between CFS subjects in Cohorts 1 and 2. HC had significantly fewer symptoms, lower MFI and higher SF-36 domain scores than CFS in both cohorts. Migraine headaches were found in $84 \%$, and tension-type headaches in $81 \%$ of Cohort 2 CFS. This compared to $5 \%$ and $45 \%$, respectively, in HC. The CFS group had migraine without aura (60\%; MO; CFS+MO), with aura (24\%; CFS+MA), tension headaches only (12\%), or no headaches (4\%). Co-morbid tension and migraine headaches were found in $67 \%$ of CFS. CFS+MA had higher severity scores than CFS+MO for the sum of scores for poor memory, dizziness, balance, and numbness ("Neuro-construct", $p=0.002$ ) and perceived heart rhythm disturbances, palpitations and noncardiac chest pain ("Cardio-construct"; $p=0.045$, t-tests after Bonferroni corrections). CFS+MO subjects had lower pressure-induced pain thresholds (2.36 kg [1.95-2.78; 95\% C.I.] $\mathrm{n}=40)$ and a higher prevalence of fibromyalgia (47\%; 1990 criteria) compared to HC (5.23 kg [3.95-6.52] $\mathrm{n}=20$; and 0\%, respectively). Sumatriptan was beneficial for 13 out of 14 newly diagnosed CFS migraine subjects.
\end{abstract}

Conclusions: CFS subjects had higher prevalences of MO and MA than HC, suggesting that mechanisms of migraine pathogenesis such as central sensitization may contribute to CFS pathophysiology.

Clinical Trial Registration: Georgetown University IRB \# 2006-481

ClinicalTrials.gov NCT00810329

\section{Background}

Headaches are common complaints in Chronic Fatigue Syndrome (CFS) and fibromyalgia (FM) [1,2]. However, the characteristics of these headaches are poorly defined with regards to the International Headache Society criteria (IHS) [3].

\footnotetext{
* Correspondence: baraniuj@georgetown.edu

Division of Rheumatology, Immunology and Allergy, Room 3004F, $3^{\text {rd }}$ Floor PHC Building, Georgetown University, 3800 Reservoir Road, NW, Washington,
} DC 20007-2197 USA

\section{Biomed Central}

(C) 2011 Ravindran et al; licensee BioMed Central Ltd. This is an Open Access article distributed under the terms of the Creative Commons Attribution License (http://creativecommons.org/licenses/by/2.0), which permits unrestricted use, distribution, and reproduction in any medium, provided the original work is properly cited.
The CFS case designation requires a 6 month history of persistent, unexplained fatigue that causes significant impairment of activity, plus 4 of 8 associated criteria [1]. These criteria include exertional exhaustion, cognitive and sleep disturbances, and diffuse bodily pain including headaches. Fatigue was verified using a 5 point anchored ordinal scale [4] and the Multidimensional Fatigue Inventory [5]. Disability and impaired quality of life were confirmed using the Medical Outcomes Survey Short Form 36 (SF-36) [6]. Headache severity was 
assessed by a 5 point ordinal scale [4]. Pain symptoms were compared between groups using the McGill Pain Short Form [7]. Acute and chronic medical, surgical and psychiatric conditions were ruled out by history and physical examinations.

Headaches and other CFS related symptoms overlap with fibromyalgia (FM) criteria. The 1990 American College of Rheumatology (ACR) research definition of FM required 3 months of unexplained, widespread pain plus tenderness to manual thumb pressure at $\geq 11$ of 18 traditional tender points [8]. This definition has been replaced by the 2010 FM criteria [9] that emphasize subjective assessments of widespread pain, fatigue, unrefreshing sleep, and cognitive difficulties. The new criteria allow considerable overlap between CFS and FM conditions.

The most prevalent headaches in the general population are tension - type (45\%), migraine (12\%), sinus $(3 \%)$, and medication overuse headaches $(1-2 \%)$ $[3,10,11]$. Tension - type $(\mathrm{T})$ headaches are defined by bilateral, pressing or nonpulsatile cephalgia of mild to moderate intensity that may last 30 minutes to 7 days. They are not aggravated by routine physical activity such as walking or stair climbing.

Migraine is diagnosed by having at least 5 episodes lasting 4 to $72 \mathrm{hr}$ with at least 2 of the following criteria: (i) unilateral location; (ii) pulsatile quality; (iii) moderate to severe pain intensity; and (iv) aggravation by physical activities or active avoidance of movement. Either nausea \pm emesis, or photophobia and phonophobia must occur. Migraines are subdivided into migraine with aura (MA; $20 \%$ to $30 \%$ of migraineurs) and migraine without aura (MO) $[3,12,13]$. The focal sensory phenomena of the aura involves either homonymous visual symptoms such as flickering lights, rotating discs, photosensitivity, and loss of vision, or unilateral somatosensory disturbances such as paresthesias or numbness. Symptoms appear gradually over 5 to 20 minutes and last less than 60 minutes. The aura must be detected at least twice. Motor function is not affected. The headache phase of the migraine attack usually begins within 60 minutes after the end of the aura, but sometimes is delayed for several hours. In some cases, pain can be completely absent. Multiple avenues of investigation including brain magnetic resonance imaging (MRI) techniques have associated auras with the concentric expansion of severe and prolonged brain cortex electrical depolarization, neurotransmitter release, vasoconstriction and reactive hyperemia known as cortical spreading depression [14]. Increased pain sensitivity (hyperalgesia) may occur in both MO and MA [15] due to dysfunctional pain regulatory mechanisms during central sensitization [16].

Since $67 \%$ of migraine subjects meet CFS criteria [2], we propose that mechanisms of migraine may play roles in CFS pathophysiology. If so, CFS subjects should have elevated rates of migraine headaches compared to control subjects. Mechanisms that differentiate MO from MA may also be present and permit subgroup analysis in CFS.

\section{Methods}

Two cohorts of CFS [1] and healthy control (HC) subjects were recruited in sequential order (Cohort 1 then Cohort 2) using identical advertisements in the community (e.g. newspapers) and the tertiary medical center (e.g. posters), and information from websites [17,18]. All subjects gave signed informed consent to take part in this IRB - approved study.

History and physical examinations assessed the CFS case designation criteria. "CFS" was designated by findings of significant, unexplained fatigue lasting at least 6 months plus the presence of at least 4 of 8 ancillary criteria: (i) problems with concentration or memory; (ii) sleep disturbances; (iii) exertional exhaustion that typically developed $24 \mathrm{hr}$ after excessive physical or mental effort; (iv) muscle pain; (v) joint pain; (vi) headaches; (vii) sore throat; and (viii) sore lymph node regions in the cervical, axillary or inguinal areas [1]. These CFS symptoms were scored in nominal fashion as "present" or "absent". In addition, subjects scored the severity of each symptom in the previous 6 months using a 5 point, anchored ordinal scale [4]. Scores were 0 for no symptom, 1 for trivial, 2 for mild, 3 for moderate and 4 for severe complaints. Inclusion of "trivial" allowed subjects to acknowledge complaints that were present but not bothersome enough to warrant treatment or other lifestyle adaptations [19]. Subjects with untreated endocrine, major psychiatric, cardiovascular, infectious (e.g. HIV), neoplastic, and other chronic diseases that may have accounted for fatigue, body pain, headache or other symptoms were excluded.

Cohort 1 was assessed by a series of questionnaires, history and physical examinations. Different combinations of questionnaires were used during their recruitment period. Preliminary results from Cohort 1 suggested an increased prevalence of migraine in CFS compared to $\mathrm{HC}$.

Next, Cohort 2 was recruited. Subjects completed an optimized set of questionnaires and had formalized clinical interviews to diagnose migraine with (MA) and without (MO) aura, and tension - type (T) headaches based on IHS criteria (as outlined in the Introduction) [3]. CFS subjects were classified as CFS+MA, CFS+MO, and CFS $+\mathrm{T}$, respectively. About two - thirds of CFS +MA and CFS+MO subjects had co-morbid tensiontype headaches. For statistical convenience, the CFS+T group included 3 subjects with no headaches.

The Multidimensional Fatigue Inventory was used to verify the presence of significant physical, mental, and 
other fatigue measures [5]. Quality of life (disability) was assessed by the Medical Outcomes Survey Short Form 36 (SF-36) domain scores [6]. Pain complaints were subjectively assessed using the McGill Pain Short Form with its Affective, Sensory and Total Scores [7]. Subjects completed a multisystem complaints questionnaire that evaluated the nominal presence or absence of migraine and tension headaches, musculoskeletal, airway, thoracic, bowel, bladder and other symptoms over the previous 3 months [4].

The frequencies of several symptoms from individual systems were found to be highly correlated with each other in preliminary studies. Therefore, questionnaires were modified to also score the severities of each symptom. The same 0 to 4 point, anchored, ordinal scale was used, and data collected for some Cohort 1 and all Cohort 2 subjects. The severity scores for the selected symptoms were again found to correlate with each other and the Fatigue Severity Score. The sum of severity scores for numbness in the arms and legs, problems with memory, dizziness and balance was calculated and accounted for $32 \%$ of the explained variance $\left(R^{2}\right)$ between these queries and the Fatigue Score. This sum was defined as the "Neuro-construct" (score range of 0 to 16). A "Cardio-construct" was developed as the sum of scores for rapid heart rate, irregular heart rate, palpitations, and chest pain (range 0 to 16). The explained variance was $30 \%$.

FM was assessed using the 1990 American College of Rheumatology (ACR) research definition. Diagnosis of FM required 3 months of unexplained, widespread pain affecting all 4 quadrants of the body and the axial skeleton, plus tenderness to manual thumb pressure $(\sim 4 \mathrm{~kg})$ at $\geq 11$ of 18 traditional tender points [8]. Pressure induced pain thresholds were measured by pushing a strain gauge tipped with a $1 \mathrm{~cm}^{2}$ rubber tip (dolorimeter) at a rate of $1 \mathrm{~kg} / \mathrm{sec}$ on the same 18 anatomical sites. The average was the systemic pain threshold $(\mathrm{kg})$. The pressure required to cause pain was also measured over the frontal, ethmoid and maxillary paranasal sinus regions. The average was the sinus pain threshold [20].

Means and 95\% confidence intervals were calculated for each variable in the HC and CFS groups [21,22]. Cohort $1 \mathrm{HC}$ and CFS outcomes were compared using 2-tailed unpaired Student's t-tests with Bonferroni corrections for multiple comparisons $(\mathrm{p} \times 138$ comparitors) to identify significant differences. Fisher's Exact tests evaluated differences in proportions [21]. Significance was ascribed to $\mathrm{p} \leq 0.05$.

The Cohort $2 \mathrm{HC}$ and CFS and headache subtype data were compared by analysis of variance (ANOVA). If significant, variables were compared by 2 -tailed unpaired Student's t-tests with Bonferroni corrections. Fisher's Exact tests were used as appropriate.

\section{Results}

\section{Demographics, Disability, and Fatigue}

There were no significant differences in age or gender distribution between $\mathrm{HC}$ and CFS subjects in either Cohort 1 or Cohort 2 after Bonferroni corrections of $\mathrm{p}$ values (Table 1). There were no significant differences of age, gender, or body mass index (BMI) for Cohort 2 $\mathrm{HC}$ and the CFS plus headache subtypes.

Most of the CFS subjects from both cohorts had rapid onset of CFS symptoms following an initiating event. Twenty-three of the Cohort 2 CFS subjects reported motor vehicle accidents, head trauma, or concussions within 5 years of the onset of their migraines (34\%). Five felt they had severe flu-like illnesses that never improved. Three gave histories of prolonged, high dose exposures to volatile organic compounds, and two stated symptoms began soon after extensive series of immunizations. Three had perimenstrual migraines that predated their CFS.

The HC groups within both cohorts had significantly better quality of life (higher scores) for all domains of the SF-36 compared to CFS subjects (Table 2). Role Emotional and Mental Health domains for the Cohort 2 CFS headache subgroups were not as significantly different from $\mathrm{HC}(0.05>\mathrm{p}>0.03)$ as for the other domains $(\mathrm{p} \leq 0.0003)$. The Multidimensional Fatigue Inventory domains were significantly higher in CFS than $\mathrm{HC}$ in both cohorts, and for the 3 CFS plus headache subgroups in Cohort 2 (Table 3 ). These results indicated that the two cohorts of control and CFS subjects were comparable to each other.

\section{Headaches}

Headache types were first assessed by self - report questionnaires. HC reported migraines in 12\% (Cohort 1) and $16 \%$ (Cohort 2), and tension headaches in $22 \%$ and $28 \%$, respectively. Migraines were reported to be more prevalent in the Cohort 2 CFS group (69\%) compared to Cohort 1 (39\%). The point prevalence rates for tension type headaches were not significantly different between Cohort 1 (62\%) and 2 (76\%) CFS groups. The combination of migraine plus tension headaches was claimed to be present in $3 \%$ of $\mathrm{HC}$ and $61 \%$ of CFS in Cohort 1. This combination was present in $11 \%$ of $\mathrm{HC}$ and $60 \%$ of CFS in Cohort 2.

Cohort 2 subjects were interviewed using IHS criteria to determine their headache type. Point prevalences in $\mathrm{HC}(\mathrm{n}=21)$ were $16 \%$ migraine, $28 \%$ tension and $11 \%$ with both. In contrast to questionnaires, interviews of these $\mathrm{HC}$ subjects identified migraine in $5 \%$, and tension headaches in $45 \%$. Interviews of 67 CFS subjects identified migraine in $84 \%$, tension headaches in $81 \%$, and both types in $67 \%$. MO was found in $60 \%(40 / 67)$, and 
Table 1 Demographics for Cohorts 1 and 2 (mean [95\% confidence intervals]; and number with percentage)

\begin{tabular}{|c|c|c|c|c|c|c|c|}
\hline & & nort 1 & & & hort 2 & & \\
\hline & $\mathrm{HC}$ & CFS & $\mathrm{HC}$ & CFS & CFS+MO & $\mathrm{CFS}+\mathrm{MA}$ & $\mathrm{CFS}+\mathrm{T}$ \\
\hline $\mathrm{N}$ & 368 & 203 & 21 & 67 & 40 & 16 & 11 \\
\hline Age & $\begin{array}{l}41.1 \\
{[39.7-42.5]}\end{array}$ & $\begin{array}{l}44.6 \\
{[42.9-46.2]}\end{array}$ & $\begin{array}{r}42.1 \\
{[36.3-47.9]}\end{array}$ & $\begin{array}{r}46.1 \\
{[43.7-48.6]}\end{array}$ & $\begin{array}{r}45.4 \\
{[42.3-48.5]}\end{array}$ & $\begin{array}{r}46.5 \\
{[42.4-50.6]}\end{array}$ & $\begin{array}{r}48.4 \\
{[40.5-56.2]}\end{array}$ \\
\hline Male & 85 (23\%) & 244 (12\%) & $13(62 \%)$ & 23 (34\%) & 11 (28\%) & $6(38 \%)$ & $6(55 \%)$ \\
\hline BMI & & & $\begin{array}{r}27.6 \\
{[25.0-30.2]}\end{array}$ & $\begin{array}{r}29.3 \\
{[26.7-30.8]}\end{array}$ & $\begin{array}{r}29.2 \\
{[27.1-31.3]}\end{array}$ & $\begin{array}{r}29.4 \\
{[25.7-33.1]}\end{array}$ & $\begin{array}{r}29.7 \\
{[24.2-33.3]}\end{array}$ \\
\hline Course & & Rap & nth) & 48 (71\%) & 32 (81\%) & 14 (87\%) & $3(23 \%)$ \\
\hline & & & & 19 (29\%) & $8(19 \%)$ & $2(13 \%)$ & $8(77 \%)$ \\
\hline
\end{tabular}

MA in 24\% (16/67). Two CFS subjects had migraines that were intermittently associated with auras. Tension headaches were present in $78 \%(31 / 40)$ of $\mathrm{MO}$ and $88 \%$ $(14 / 16)$ of MA. The CFS+T group $(n=11)$ included 3 with no headaches.

CFS subjects attributed the high prevalences of headaches to their impression that head pain was a usual and often daily manifestation of the severe fatigue and general pain syndrome they experienced. They were often unaware of MO headaches and the potential to use beneficial migraine treatments. Nonsteroidal antiinflammatory drugs were used by all subjects, raising the possibility of medication overuse headaches as a complicating factor in CFS.
Migraine frequency and treatment information were obtained from 51 of the 67 CFS subjects. Headaches occurred on a yearly to monthly basis in 27 subjects (53\%). Twenty of these had been previously diagnosed, and 7 were treated with a triptan drug. Half of this subset $(10 / 20)$ had no specific headache evaluation or treatment plan. Three subjects were symptomatic with migraine during their interviews, and received new diagnoses at that time. All 3 responded to sumatriptan.

Headaches were present for 1 to 7 days per week in $47 \%$ of the 51 CFS migraine subjects. Only 14 of these 24 had been previously diagnosed, and only 3 were prescribed triptan drugs. Of the 11 with active headaches during the interviews that led to new migraine

Table 2 MOS-SF-36 Quality of Life Domains for Cohorts 1 and 2 (mean [95\% confidence intervals]; probability)

\begin{tabular}{|c|c|c|c|c|c|c|c|}
\hline \multirow[b]{2}{*}{ Domain } & \multicolumn{2}{|c|}{ Cohort 1} & \multicolumn{5}{|c|}{ Cohort 2} \\
\hline & $\begin{array}{l}\mathrm{HC} \\
\mathrm{n}=295\end{array}$ & $\begin{array}{l}\text { CFS * } \\
\mathrm{n}=145\end{array}$ & $\begin{array}{r}H C \\
n=19\end{array}$ & $\begin{array}{l}\text { CFS ** } \\
\mathrm{n}=49\end{array}$ & $\begin{array}{r}\mathrm{CFS}+\mathrm{MO}^{* *} \\
\mathrm{n}=28\end{array}$ & $\begin{array}{r}\mathrm{CFS}+\mathrm{MA}^{* *} \\
\mathrm{n}=12\end{array}$ & $\begin{array}{r}\mathrm{CFS}+\mathrm{T}^{* *} \\
\mathrm{n}=9\end{array}$ \\
\hline Physical Functioning & $\begin{array}{l}71.6 \\
{[67.8-75.4]}\end{array}$ & $\begin{array}{l}47.6 \\
{[43.4-52.1]} \\
p<10^{-10}\end{array}$ & $\begin{array}{r}91.1 \\
{[82.4-99.7]}\end{array}$ & $\begin{array}{r}41.4 \\
{[34.6-48.2]} \\
p<10^{-10}\end{array}$ & $\begin{array}{r}43.7 \\
{[35.5-51.9]} \\
p=10^{-9}\end{array}$ & $\begin{array}{r}28.8 \\
{[15.6-41.9]} \\
p=10^{-8}\end{array}$ & $\begin{array}{r}51.7 \\
{[34.5-68.8]} \\
p=0.0001\end{array}$ \\
\hline Social Functioning & $\begin{array}{l}67.4 \\
{[63.2-71.6]}\end{array}$ & $\begin{array}{l}46.4 \\
{[41.8-51.0]} \\
p=10^{-9}\end{array}$ & $\begin{array}{r}87.5 \\
{[76.5-98.5]}\end{array}$ & $\begin{array}{r}26.9 \\
{[21.0-32.8]} \\
p<10^{-10}\end{array}$ & $\begin{array}{r}25.5 \\
{[17.9-33.0]} \\
p<10^{-10}\end{array}$ & $\begin{array}{r}23.9 \\
{[9.3-38.4]} \\
p=10^{-7}\end{array}$ & $\begin{array}{r}35.9 \\
{[26.2-45.7]} \\
P=0.000005\end{array}$ \\
\hline Role-Physical & $\begin{array}{l}60.5 \\
{[63.2-71.6]}\end{array}$ & $\begin{array}{l}18.5 \\
{[13.3-23.7]} \\
p<10^{-10}\end{array}$ & $\begin{array}{r}76.3 \\
{[57.8-94.9]}\end{array}$ & $\begin{array}{r}5.6 \\
{[0.8-10.4]} \\
p<10^{-10}\end{array}$ & $\begin{array}{r}8.0 \\
{[0.5-15.6]} \\
p=10^{-9}\end{array}$ & $\begin{array}{r}4.2 \\
{[-4.0-12.3]} \\
p=10^{-6}\end{array}$ & $P=0.000009$ \\
\hline Role-Emotional & $\begin{array}{l}71.6 \\
{[62.8-80.3]}\end{array}$ & $\begin{array}{l}53.3 \\
{[46.2-60.5]} \\
p=0.008\end{array}$ & $\begin{array}{r}86.0 \\
{[72.5-99.5]}\end{array}$ & $\begin{array}{r}57.6 \\
{[44.8-70.5]}\end{array}$ & $\begin{array}{r}59.3 \\
{[42.0-76.5]} \\
p=0.03\end{array}$ & $\begin{array}{r}55.6 \\
{[28.5-82.7]} \\
p=0.04\end{array}$ & $\begin{array}{r}55.6 \\
{[24.8-86.4]} \\
p=0.048\end{array}$ \\
\hline Mental Health & $\begin{array}{l}66.8 \\
{[63.0-70.5]}\end{array}$ & $\begin{array}{l}58.4 \\
{[54.9-61.9]} \\
p=0.006\end{array}$ & $\begin{array}{r}79.2 \\
{[74.0-84.3]}\end{array}$ & $\begin{array}{r}62.6 \\
{[57.0-68.3]}\end{array}$ & $\begin{array}{r}64.9 \\
{[57.9-71.8]} \\
p=0.005\end{array}$ & $\begin{array}{r}59.7 \\
{[45.1-74.2]} \\
p=0.007\end{array}$ & $\begin{array}{r}59.6 \\
{[48.1-71.0]} \\
p=0.001\end{array}$ \\
\hline Vitality & $\begin{array}{l}50.1 \\
{[47.1-53.1]}\end{array}$ & $\begin{array}{l}25.4 \\
{[22.3-28.5]} \\
p<10^{-10}\end{array}$ & $\begin{array}{r}66.1 \\
{[56.5-75.8]}\end{array}$ & $\begin{array}{r}13.9 \\
{[10.5-17.2]} \\
p<10^{-10}\end{array}$ & $\begin{array}{r}14.8 \\
{[10.3-19.3]} \\
p<10^{-10}\end{array}$ & $\begin{array}{r}6.7 \\
{[2.1-11.2]} \\
p=10^{-10}\end{array}$ & $\begin{array}{r}20.6 \\
{[12.6-28.5]} \\
p=10^{-6}\end{array}$ \\
\hline Bodily Pain & $\begin{array}{l}60.5 \\
{[56.5-64.6]}\end{array}$ & $\begin{array}{l}35.1 \\
{[31.4-38.8]} \\
p<10^{-10}\end{array}$ & $\begin{array}{r}83.8 \\
{[72.4-95.2]}\end{array}$ & $\begin{array}{r}34.1 \\
{[28.1-40.2]} \\
p<10^{-10}\end{array}$ & $\begin{array}{r}32.8 \\
{[25.3-40.3]} \\
p=10^{-9}\end{array}$ & $\begin{array}{r}30.6 \\
{[16.2-44.9]} \\
p=10^{-6}\end{array}$ & $\begin{array}{r}42.8 \\
{[29.5-56.0]} \\
p=0.0003\end{array}$ \\
\hline General Health & $\begin{array}{l}64.5 \\
{[56.5-64.6]}\end{array}$ & $\begin{array}{l}38.3 \\
{[34.3-42.3]} \\
p<10^{-10}\end{array}$ & $\begin{array}{r}76.8 \\
{[69.5-84.2]}\end{array}$ & $\begin{array}{r}33.0 \\
{[27.8-38.2]} \\
p<10^{-10}\end{array}$ & $\begin{array}{r}36.2 \\
{[28.3-44.1]} \\
p=10^{-8}\end{array}$ & $\begin{array}{r}28.8 \\
{[19.9-37.6]} \\
p=10^{-8}\end{array}$ & $\begin{array}{r}29.1 \\
{[20.9-37.4]} \\
p=10^{-8}\end{array}$ \\
\hline
\end{tabular}

2-tailed unpaired Student's t-tests with Bonferroni corrections following ANOVA $(p<0.05)$ : ${ }^{*}$ vs. HC of Cohort 1 and ${ }^{*}$ vs. HC of Cohort 2. 
Table 3 Multidimensional Fatigue Inventory Domains (mean [95\% confidence intervals]; probability)

\begin{tabular}{|c|c|c|c|c|c|c|c|}
\hline \multirow[b]{2}{*}{ Domains } & \multicolumn{2}{|c|}{ Cohort 1} & \multicolumn{5}{|c|}{ Cohort 2} \\
\hline & $\begin{array}{l}\mathrm{HC} \\
\mathrm{n}=300\end{array}$ & $\begin{array}{l}\text { CFS * } \\
n=170\end{array}$ & $\begin{array}{r}\mathrm{HC} \\
\mathrm{n}=19 \\
\end{array}$ & $\begin{array}{l}\text { CFS ** } \\
\mathrm{N}=49 \\
\end{array}$ & $\begin{array}{r}\mathrm{CFS}+\mathrm{MO}^{* *} \\
\mathrm{n}=\mathbf{2 8}\end{array}$ & $\begin{array}{r}\mathrm{CFS}+\mathrm{MA} A^{* *} \\
\mathrm{~N}=12\end{array}$ & $\begin{array}{r}\mathrm{CFS}+\mathrm{T} * * \\
\mathrm{n}=9\end{array}$ \\
\hline General Fatigue & $\begin{array}{l}10.4 \\
{[9.9-10.9]}\end{array}$ & $\begin{array}{l}16.4 \\
{[15.9-16.9]} \\
p<10^{-10}\end{array}$ & $\begin{array}{r}8.2 \\
{[6.7-9.6]}\end{array}$ & $\begin{array}{r}17.9 \\
{[17.2-18.6]} \\
p<10^{-10}\end{array}$ & $\begin{array}{r}18.3 \\
{[17.5-19.1]} \\
p<10^{-10}\end{array}$ & $\begin{array}{r}18.5 \\
{[17.0-20.0]} \\
p=10^{-10}\end{array}$ & $\begin{array}{r}15.9 \\
{[13.9-17.8]} \\
p=10^{-6}\end{array}$ \\
\hline Physical Fatigue & $\begin{array}{l}9.4 \\
{[8.9-9.9]}\end{array}$ & $\begin{array}{l}14.6 \\
{[14.0-15.2]} \\
p<10^{-10}\end{array}$ & $\begin{array}{r}8.1 \\
{[5.8-10.3]}\end{array}$ & $\begin{array}{r}16.0 \\
{[15.1-16.9]} \\
p<10^{-10}\end{array}$ & $\begin{array}{r}16.3 \\
{[15.1-17.5]} \\
p=10^{-8}\end{array}$ & $\begin{array}{r}16.3 \\
{[14.6-17.9]} \\
p=0.00002\end{array}$ & $\begin{array}{r}14.8 \\
{[12.2-16.5]} \\
p=0.002\end{array}$ \\
\hline Reduced Activity & $\begin{array}{l}8.4 \\
{[8.0-8.8]}\end{array}$ & $\begin{array}{l}12.7 \\
{[12.1-13.4]} \\
p<10^{-10}\end{array}$ & $\begin{array}{r}7.4 \\
{[5.7-9.2]}\end{array}$ & $\begin{array}{r}16.2 \\
{[15.2-17.1]} \\
p<10^{-10}\end{array}$ & $\begin{array}{r}16.3 \\
{[15.0-17.5]} \\
p<10^{-10}\end{array}$ & $\begin{array}{r}17.4 \\
{[15.8-19.1]} \\
p=10^{-8}\end{array}$ & $\begin{array}{r}14.3 \\
{[12.2-16.5]} \\
p=0.00001\end{array}$ \\
\hline Reduced Motivation & $\begin{array}{l}8.2 \\
{[7.6-8.7]}\end{array}$ & $\begin{array}{l}11.1 \\
{[10.5-11.7]} \\
p<10^{-10}\end{array}$ & $\begin{array}{r}8.2 \\
{[6.7-9.7]}\end{array}$ & $\begin{array}{r}11.9 \\
{[10.7-13.1]} \\
P=0.001\end{array}$ & $\begin{array}{r}11.8 \\
{[10.1-13.4]} \\
p=0.005\end{array}$ & $\begin{array}{r}13.0 \\
{[10.3-15.7]} \\
p=0.003\end{array}$ & $\begin{array}{r}10.7 \\
{[8.8-12.5]}\end{array}$ \\
\hline Mental Fatigue & $\begin{array}{l}8.8 \\
{[8.3-9.3]}\end{array}$ & $\begin{array}{l}13.2 \\
{[12.5-13.9]} \\
p<10^{-10}\end{array}$ & $\begin{array}{r}8.5 \\
{[6.9-10.1]}\end{array}$ & $\begin{array}{r}15.0 \\
{[13.8-16.1]} \\
P=10^{-8}\end{array}$ & $\begin{array}{r}14.7 \\
{[13.2-16.1]} \\
p=10^{-6}\end{array}$ & $\begin{array}{r}16.8 \\
{[14.7-18.8]} \\
p=10^{-6}\end{array}$ & $\begin{array}{r}13.3 \\
{[10.4-16.2]} \\
p=0.004\end{array}$ \\
\hline
\end{tabular}

2-tailed unpaired Student's t-tests with Bonferroni corrections following ANOVA ( $<<0.05)$ : * vs. HC of Cohort 1 and ** vs. HC of Cohort 2.

diagnoses, 10 had beneficial responses to sumatriptan within 12 hours. In total, 13 out of 14 newly diagnosed migraine subjects responded to sumatriptan. This indicates that diagnosis of migraine and its treatment with triptans was of significant benefit in CFS subjects. Migraines were under diagnosed and under treated in CFS subjects.

\section{CFS Criteria}

The severity scores for each of the 9 CFS criteria (range 0 to 4 for each item) were compiled to examine differences based on headache subtypes. Fatigue Severity Scores were significantly lower in $\mathrm{HC}$ than each of the CFS headache subgroups and the composite group of all CFS subjects ( $\mathrm{p}<10^{-7}$ by 2 -tailed unpaired Student's t-tests with Bonferroni corrections following significant ANOVA) (Figure 1). CFS and CFS headache subgroup scores were significantly higher than HC $(\mathrm{p}<0.006)$ except for sore throat in CFS+MA ( $p=0.02)$, and headache $(\mathrm{p}=0.03)$ and sore lymph nodes $(\mathrm{p}=0.04)$ in the CFS $+\mathrm{T}$ subgroup. Headache Severity Scores were significantly higher in CFS $+\mathrm{MO}, \mathrm{CFS}+\mathrm{MA}$ and total CFS groups compared to $\mathrm{HC}$ ( $\mathrm{p}=10^{-8}$ by ANOVA; $\mathrm{p} \leq 10^{-6}$ for each comparison after Bonferroni comparisons).

\section{Other questionnaires}

McGill Pain Scores were significantly higher in the CFS than $\mathrm{HC}$ groups of Cohorts 1 and 2 (Table 4). Both the $\mathrm{CFS}+\mathrm{MO}$ and CFS+MA subtypes had significantly higher scores than $\mathrm{HC}$ in Cohort 2 ( $\mathrm{p}=0.0027$ by ANOVA and $\mathrm{p}<0.007$ by t-tests). These differences were driven by the Sensory Subscale. "Neuro-construct" scores were highest in CFS+MA (11.4 out of 16) (Table 4). CFS+MA scores were significantly higher than $\mathrm{HC}\left(\mathrm{p}=10^{-8}\right)$, CFS $+\mathrm{MO}(\mathrm{p}=0.002)$ and CFS $+\mathrm{T}(\mathrm{p}=0.00002$; t-tests $)$.
"Cardio-construct" scores were significantly higher for CFS+MA (5.9 out of 16) than CFS+MO ( $p=0.045$; t-tests) and CFS+T ( $\mathrm{p}=0.049)$. These results were consistent with the elevated scores of Cohort 1 CFS subjects (Table 4).

\section{Fibromyalgia and dolorimetry}

Significantly more CFS+MO (55.3\%) and CFS+MA (46.2\%) subjects complained of widespread pain in all four quadrants and their axial skeleton compared to $\mathrm{HC}$ (10.0\%; $p=0.0010$ by Fisher's Exact tests vs. All CFS) (Table 5). Positive tender points $(\geq 11 / 18)$ were found more commonly in CFS (55.4\%) than HC (5.6\%; p = 0.00005). Based on the 1990 ACR criteria [4], fibromyalgia was present in $37.7 \%$ of CFS, $47.4 \%$ of CFS+MO, $28.5 \%$ of CFS+MA, and $11.1 \%$ in CFS+T, but none of the $\mathrm{HC}$ subjects ( $\mathrm{p}=0.0022$ by ANOVA).

The average pressure causing pain at the 18 tender points was measured by dolorimetry. The CFS+MO subgroup had a significantly lower pain threshold $(2.36 \mathrm{~kg})$ compared to $\mathrm{HC}(5.23 \mathrm{~kg} ; \mathrm{p}=0.00001$ by Bonferroni corrected t-test and $\mathrm{p}=0.0006$ by ANOVA) (Table 5). Pain thresholds were not correlated with age or gender (data not shown). Tenderness was assessed over the facial sinus regions. CFS subjects had lower pain thresholds $(1.02 \mathrm{~kg})$ than $\mathrm{HC}(1.91 \mathrm{~kg} ; \mathrm{p}=0.0002$, t-test), with the CFS+MO subgroup being the most tender $(0.87 \mathrm{~kg}$; $\mathrm{p}=0.00001)$.

\section{Discussion}

CFS, FM and headaches were defined by personal history and physical examinations in this study rather than by surveys as reported previously $[2,23,24]$. The headache interview used for Cohort 2 identified the frequencies of migraine subtypes and tension headache in both 


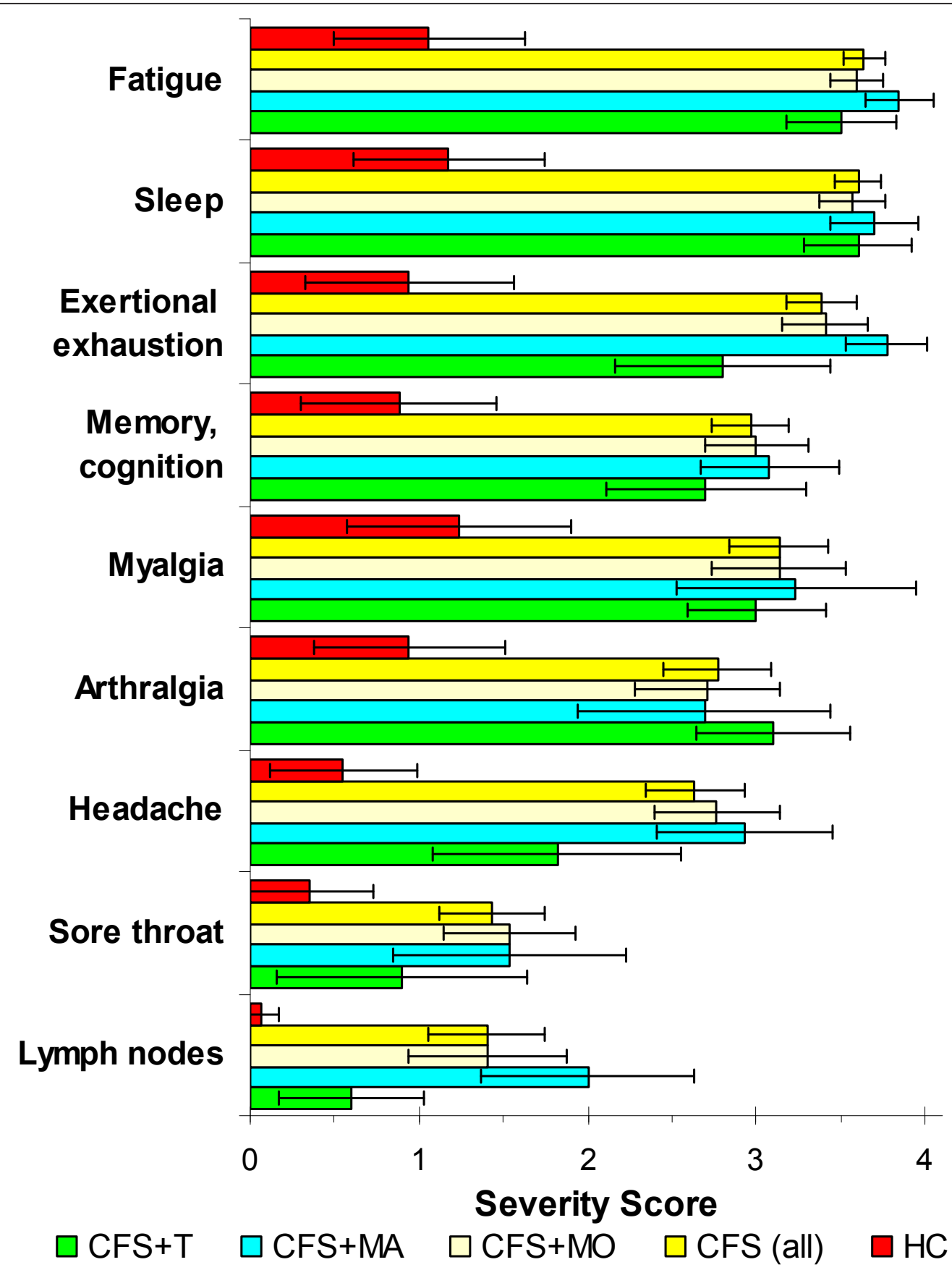

Figure 1 CFS symptom severity scores for Cohort 2. Symptom severities were scored on ordinal scales from 0 to 4 . HC (red columns) had significantly lower scores for each item (mean; 95\% C.I. error bars) compared to all CFS (yellow columns) ( $\mathrm{p} \leq 0.006$ after Bonferonni corrections). HC scores were also significantly lower than all the CFS headache subtypes and items except sore throat in CFS+T (green bar). CFS+MA (blue columns) had significantly higher scores than CFS+T for exertional exhaustion $(p=0.036)$ and sore lymph nodes $(p=0.017)$.

CFS and HC groups. The self-report questionnaires gave comparable results for Cohorts 1 and 2. However, the questionnaire findings were not accurate when compared to the structured interviews. The interviews provided credibility to the presence of CFS+MA and CFS $+\mathrm{T}$ subgroups despite their small sample sizes. The interviews also demonstrated the higher rates of tension headaches in $\mathrm{HC}$, and migraine without aura (MO) in CFS. CFS subjects with tension headaches (CFS+T) tended to have less severe complaints compared to the migraine subtypes. Inclusion of quality of life SF-36 and fatigue (MFI) questionnaires confirmed the disability 
Table 4 Subjective scores that were significantly different from HC and CFS+MA (mean [95\% C.I.]; probability)

\begin{tabular}{|c|c|c|c|c|c|c|c|}
\hline & \multicolumn{2}{|c|}{ Cohort 1} & \multicolumn{5}{|c|}{ Cohort 2} \\
\hline & $\mathrm{HC}$ & CFS & $\mathrm{HC}$ & All CFS & $\mathrm{CFS}+\mathrm{MO}$ & CFS+MA & $\mathrm{CFS}+\mathrm{T}$ \\
\hline Headache Severity Score & $\begin{array}{l}0.85 \\
{[0.69-1.01]} \\
N=191\end{array}$ & $\begin{array}{l}2.64 \\
{[2.45-2.83]} \\
n=152 \\
p<10^{-10} *\end{array}$ & $\begin{array}{r}0.55 \\
{[0.11-0.99]} \\
n=20\end{array}$ & $\begin{array}{r}2.63 \\
{[2.33-2.93]} \\
n=63 \\
p<10^{-9} * *\end{array}$ & $\begin{array}{r}2.76 \\
{[2.39-3.13]} \\
n=38 \\
p<10^{-8 * *}\end{array}$ & $\begin{array}{r}2.93 \\
{[2.43-3.43]} \\
n=14 \\
p=10^{-6 * *}\end{array}$ & $\begin{array}{r}1.82 \\
{[1.08-2.56]} \\
n=11 \\
p=0.03 \text { ** }\end{array}$ \\
\hline McGill Sensory Score & $\begin{array}{l}6.5 \\
{[5.2-8.8]} \\
n=109\end{array}$ & $\begin{array}{l}8.8 \\
{[7.0-10.5]} \\
n=55 \\
p=0.002 *\end{array}$ & $\begin{array}{r}4.3 \\
{[0.9-7.7]} \\
n=18\end{array}$ & $\begin{array}{r}13.9 \\
{[11.5-16.3]} \\
n=44 \\
p=0.0004^{* *}\end{array}$ & $\begin{array}{r}13.6 \\
{[10.5-16.6]} \\
n=24 \\
p=0.002^{* *}\end{array}$ & $\begin{array}{r}17.5 \\
{[11.6-23.4]} \\
n=12 \\
p=0.002 * *\end{array}$ & $\begin{array}{r}9.50 \\
{[7.0-12.0]} \\
n=8\end{array}$ \\
\hline Neuro-Construct & $\begin{array}{l}2.39 \\
{[1.58-3.20]} \\
n=57\end{array}$ & $\begin{array}{l}7.00 \\
{[4.91-9.01]} \\
n=21 \\
p=0.000005^{*}\end{array}$ & $\begin{array}{r}1.71 \\
{[0.36-3.06]} \\
n=17\end{array}$ & $n=48 p=0.00003^{* *}$ & $\begin{array}{r}6.33 \\
{[4.92-7.74]} \\
n=30 \\
p=0.0007^{* *} \\
p=0.002^{* * *}\end{array}$ & $\begin{array}{r}11.4 \\
{[10.3-12.5]} \\
n=10 \\
p=10^{-8 * *}\end{array}$ & $\begin{array}{r}4.50 \\
{[2.84-6.16]} \\
n=8 \\
p=0.00002^{* * *}\end{array}$ \\
\hline Cardio-Construct & $\begin{array}{l}1.46 \\
{[0.79-2.13]} \\
n=57\end{array}$ & $\begin{array}{l}2.86 \\
{[1.45-4.27]} \\
n=21 \\
p=0.053\end{array}$ & $\begin{array}{r}0.76 \\
{[-0.07-1.59]} \\
n=17\end{array}$ & $\begin{array}{r}3.22 \\
{[2.30-4.14]} \\
n=45 \\
p=0.02^{* *}\end{array}$ & $\begin{array}{r}2.70 \\
{[1.67-3.73]} \\
n=27 \\
p=0.045^{* * *}\end{array}$ & $\begin{array}{r}5.90 \\
{[3.55-8.25]} \\
n=10 \\
p=0.0004^{* *}\end{array}$ & $\begin{array}{r}1.63 \\
{[0.65-2.61]} \\
n=8 \\
p=0.049^{* * *}\end{array}$ \\
\hline
\end{tabular}

* vs. HC of Cohort $1 ;{ }^{* *}$ vs. HC of Cohort 2; and ${ }^{* * *}$ vs. CFS+MA using 2-tailed unpaired Student's t-tests with Bonferroni corrections after ANOVA. NeuroConstruct $=$ sum of scores for poor memory, dizziness, balance problems, and numbness in arms or legs. Cardio-Construct $=$ sum of scores for rapid heart rate, irregular heart rate, palpitations, and chest pain.

and spectrum of fatigue manifestations experienced by the CFS groups.

These data verified the high prevalence of migraine pathology in CFS [2]. The ratio of MO to MA was similar to that reported in other migraine groups $[10,12]$. We propose that mechanisms of migraine pathophysiology may contribute to other CFS symptoms in addition to headaches. If so, anti - migraine treatments may be beneficial for CFS - related symptoms even in subjects who do not have migraines. This speculation requires prospective evaluation in clinical trials.

Correlates of MO and MA suggested that aura may be associated with distinct phenotypic and pathological alterations. Neuro-construct, Cardio-construct, and McGill Pain Scores were higher in CFS+MA than CFS
$+\mathrm{MO}$. These queries relied on self-reported perceptions of dizziness and lightheadedness, peripheral numbness, thoracic sensations, and higher numbers of pain descriptors. It is not clear how these perceptions may be related to the phenomenon of aura. Vertigo has been associated with migraine as vertiginous migraines, but has not been definitively investigated for a relationship to aura $[25,26]$. The sensations of abnormal heart beat and palpitations may be related to autonomic dysregulation that is a common feature of CFS [27]. Chest pain was not related to coronary artery disease or angina as determined by history and physical examination, EKG's, and exercise stress tests in a portion of the subjects. Noncardiac chest pain with perceptions of tachycardia and palpitations may be due to esophageal spasms with

Table 5 Fibromyalgia (1990 Criteria) [8] and pressure - induced pain thresholds in Cohort 2 (mean [95\% confidence intervals]; probability)

\begin{tabular}{|c|c|c|c|c|c|}
\hline & $\begin{array}{r}H C \\
n=20\end{array}$ & $\begin{array}{l}\text { All CFS } \\
N=67\end{array}$ & $\begin{array}{r}\text { CFS+MO } \\
n=40\end{array}$ & $\begin{array}{r}\text { CFS+MA } \\
n=16\end{array}$ & $\begin{array}{l}\text { CFS+T } \\
n=10 \\
\end{array}$ \\
\hline Widespread pain & $10.0 \%$ & $\begin{array}{r}50.0 \% \\
P=0.0010^{*}\end{array}$ & $\begin{array}{r}55.3 \% \\
p=0.0006^{*}\end{array}$ & $\begin{array}{r}46.2 \\
p=0.02^{*}\end{array}$ & $33.3 \%$ \\
\hline Manual pressure at $\geq 11 / 18$ Points & $5.6 \%$ & $\begin{array}{r}55.4 \% \\
p=0.00005^{*}\end{array}$ & $\begin{array}{r}64.1 \% \\
p=0.000013^{*}\end{array}$ & $p=0.001^{*}$ & $\begin{array}{r}20.0 \% \\
p=0.014^{* *}\end{array}$ \\
\hline Fibromyalgia & $0 \%$ & $P=0.0004^{*}$ & $\begin{array}{r}47.4 \% \\
P=0.00007^{*}\end{array}$ & $p=\begin{array}{r}28.5 \% \\
0.022^{*}\end{array}$ & $p=0.03^{* *}$ \\
\hline Systemic pain threshold $(\mathrm{kg})$ & $\begin{array}{r}5.23 \\
{[3.95-6.52]}\end{array}$ & $\begin{array}{r}2.90 \\
{[2.47-3.32]} \\
p=0.0002^{+}\end{array}$ & $\begin{array}{r}2.36 \\
{[1.95-2.78]} \\
P=0.00001^{\dagger}\end{array}$ & $\begin{array}{r}3.51 \\
{[2.53-4.48]}\end{array}$ & $\begin{array}{r}3.94 \\
{[2.67-5.20]} \\
p=0.025^{\text {t+ }}\end{array}$ \\
\hline Sinus pain threshold (kg) & $\begin{array}{r}1.91 \\
{[0.37-2.45]}\end{array}$ & $p=0.0002^{\dagger}$ & $\begin{array}{r}0.87 \\
{[0.71-1.03]} \\
p=0.0001\end{array}$ & $\begin{array}{r}1.18 \\
{[0.86-1.51]}\end{array}$ & $\begin{array}{r}1.30 \\
{[0.90-1.71]}\end{array}$ \\
\hline
\end{tabular}

Fisher's Exact Test vs.* HC and vs. ${ }^{* *}$ CFS+MO. 2-tailed unpaired Student's tests with Bonferonni corrections following ANOVA ( $\left.p<0.05\right)$ vs. ${ }^{\dagger}$ HC and vs.

${ }^{++}$CFS+MO. 
nutcracker esophagus [28] or costochondritis [29] in CFS.

Conversely, CFS $+\mathrm{MO}$ showed trends for an higher prevalence of FM (1990 criteria) [8] and lower systemic and sinus pain thresholds than CFS+MA (Table 5). Additional testing will be required to determine if these measures reach statistical significance when the number of CFS+MA subjects is increased. This potential difference in tenderness (hyperalgesia) and allodynia [23] between $\mathrm{CFS}+\mathrm{MA}$ and CFS+MO was not apparent when the severities of the pain - related symptoms such as myalgia and arthralgia were compared (Figure 1). The severities of neurocognitive symptoms were also equivalent between CFS+MO and CFS+MA subgroups.

The current study was not designed to correlate triggers of migraine or the presence of an aura with precipitating factors of severe episodes of CFS complaints. Migraine triggers include fasting, premenstrual period hormonal status, lack of sleep, nasal irritants and odors [30]. Similar triggers are associated with acute worsening of CFS complaints. Future studies will be needed to identify correlates and mechanisms of aura, allodynia and hyperalgesia development in CFS migraineurs $[16,20,23]$.

The association of migraine with CFS and FM introduces a new perspective for "functional" somatization disorders. We agree with Wessely et al. [31] who stated that the existence of specific functional somatic syndromes is an artifact of medical specialization and different systems - oriented consensus definitions of these illnesses. This attitude is conveyed by the 2010 FM diagnostic criteria that overlap extensively with CFS, and remove the importance of "tender points" $[1,9]$. A further stage in the evolution of CFS, FM, irritable bowel syndrome, and other systems - based diagnoses has been proposed by Fink and Schroder with their hypothesis of Bodily Distress Syndrome [32]. A reevaluation of the pathophysiological mechanisms contributing to these seemingly disparate syndromes and individual organic disorders such as migraine may lead to the recognition of common primary pathologic, genetic and environmental diatheses that lead to overlapping and fluctuating patterns of organ - specific complaints.

\section{Conclusions}

CFS subjects have a high prevalence of migraine headaches that may be overlooked and undertreated. The proportion with an aura was similar to other migraine groups. CFS+MA was associated with higher severity scores for neural problems such as numbness and dizziness, and alterations of heart beat. The lower pressure induced pain thresholds and hyperalgesia found in the CFS $+\mathrm{MO}$ subgroup was suggestive of nociceptive hyperresponsiveness and central sensitization. Appropriate diagnosis and treatment with triptans may be beneficial for CFS subjects and their complex headaches.

\section{Support}

This project was conducted through the GeorgetownHoward Universities Center for Clinical and Translational Science and supported by the National Institutes of Health National Center for Research Resources through Grant 1UL1RR031975; U.S. Public Health Service Award R01 ES015382 from the National Institute of Environmental and Health Science; and the Congressionally Directed Medical Research Program (CDMRP) Award W81XWH-07-1-0618.

\section{Abbreviations}

IHS: International Headache Society; CFS: Chronic Fatigue Syndrome; FM: Fibromyalgia; ACR: American College of Rheumatology; MA: Migraine with aura; MO: Migraine without aura; WPI: Widespread Pain Index; WSP:

Widespread Pain; MRI: Magnetic Resonance Imaging; CSD: Cortical Spreading Depression; CSMI: Multisystem Complaints Questionnaire; MFI:

Multidimensional Fatigue Inventory; SF-36: Medical Outcomes Survey Short Form 36.

\section{Authors' contributions}

MKR and JNB made the original clinical observations, and performed the study with the assistance of the other authors. All authors have read and approved the final manuscript.

\section{Competing interests}

The authors declare that they have no competing interests.

Received: 9 July 2010 Accepted: 5 March 2011 Published: 5 March 2011

\section{References}

1. Fukuda K, Straus SE, Hickie I, Sharpe MC, Dobbins JG, Komaroff A, the International Chronic Fatigue Syndrome Study Group: The chronic fatigue syndrome: a comprehensive approach to its definition and study. Ann Intern Med 1994, 121:953-959.

2. Peres MFP, Zukerman E, Young WB, Silberstein SD: Fatigue in chronic migraine patients. Cephalagia 2002, 22:720-724.

3. Headache Classification Subcommittee of the International Headache Society: The International Classification of Headache Disorders. Cephalalgia , 2 2004, 24(Suppl 1):9-160.

4. Baraniuk JN, Clauw JD, Gaumond E: Rhinitis symptoms in chronic fatigue syndrome. Annals Allergy Asthma Immunol 1998, 81:359-365.

5. Smets EM, Garssen B, Bonke B, De Haes JC: The Multidimensional Fatigue Inventory (MFI) psychometric qualities of an instrument to assess fatigue. J Psychosom Res 1995, 39:315-325.

6. Ware JE, Sherbourne CD: The MOS 36-item short-form health survey (SF36): I. Conceptual framework and item selection. Medical Care 1995, 30:473-483.

7. Melzack R: The short-form McGill pain questionnaire. Pain 1987, 30:191-197.

8. Wolfe F, Smythe H, Yunus M, Bennett R, Bombardier C, Goldenberg D: The American College of Rheumatology 1990 criteria for the classification of fibromyalgia. Report of the multicenter criteria committee. Arthritis and Rheumatism 1990, 33:160-172.

9. Wolfe F, Clauw DJ, Fitzcharles MA, Goldenberg DL, Katz RS, Mease P, Russell AS, Russell IJ, Winfield JB, Yunus MB: The American College of Rheumatology preliminary diagnostic criteria for fibromyalgia and measurement of symptom severity. Arthritis Care Res (Hoboken) 2010, 62:600-610.

10. Robbins M, Lipton RB: The epidemiology of primary headache disorders. Semin Neurol 2010, 30:107-119.

11. Ravindran M, Baraniuk JN: The sinus headache explained. Curr Allergy Asthma Rep 2010, 10:202-209. 
12. Kelman L: The premonitory symptoms (prodrome): a tertiary care study of 893 migraineurs. Headache 2004, 44:865-872.

13. Stephen D: Atlas of Migraine and Other Headaches. London: Taylor \& Francis Group; 2005.

14. Eikermann-Haerter K, Ayata C: Cortical spreading depression and migraine. Curr Neurol Neurosci Rep 2010, 10:167-173.

15. Okifuji A, Turk DC, Marcus DA: Comparison of generalized and localized hyperalgesia in patients with recurrent headache and fibromyalgia. Psychosom Med 1999, 61:771-780.

16. Latremoliere A, Woolf CJ: Central sensitization: a generator of pain hypersensitivity by central neural plasticity. J Pain 2009, 10:895-926.

17. [http://www9.georgetown.edu/faculty/baraniuj/Site/Welcome.html].

18. [http://www.clinicaltrials.gov].

19. Wasserfallen JB, Gold K, Schulman KA, Milzman D, Baraniuk JN: Development and validation of a rhinoconjunctivitis and asthma symptom score for use as an outcome measure in clinical trials. J Allergy Clin Immunol 1997, 100:16-22.

20. Naranch K, Park YJ, Repka-Ramirez MS, Velarde A, Clauw D, Baraniuk JN: A tender sinus does not always mean rhinosinusitis. Otolaryngol Head Neck Surg 2002, 127:387-397.

21. Swinscow TDV, Campbell MJ: Statistics at Square One. BMJ Books, London 2002, 44-51.

22. Gardner MJ, Altman DG, eds: Statistics With Confidence - Confidence intervals and statistical guidelines. BMJ. London 1989, 1-140.

23. Tietjen GE, Brandes JL, Peterlin BL, Eloff A, Dafer RM, Stein MR, Drexler E, Martin VT, Hutchinson S, Aurora SK, Recober A, Herial NA, Utley C, White L, Khuder SA: Allodynia in migraine: association with comorbid pain conditions. Headache 2009, 49:1333-1344.

24. de Tommaso M, Sardaro M, Serpino C, Costantini F, Vecchio $E_{\text {, }}$ Prudenzano MP, Lamberti P, Livrea P: Fibromyalgia comorbidity in primary headaches. Cephalalgia 2009, 29:453-464.

25. Ménière P: Pathologie auriculaire. Mémoires sur une lésion de 1'oreille interne donnant lieu à des symptoms de congestion cérébrale apoplectiforme. Gaz Med Paris 1861, 16:597-601.

26. Neuhauser $H$, Lempert $\mathrm{T}$ : Vertigo and dizziness related to migraine: a diagnostic challenge. Cephalalgia 2004, 24:83-91.

27. Tak LM, Riese H, de Bock GH, Manoharan A, Kok IC, Rosmalen JG: As good as it gets? A meta-analysis and systematic review of methodological quality of heart rate variability studies in functional somatic disorders. Biol Psychol 2009, 82:101-110.

28. Frissora $\mathrm{CL}$, Koch $\mathrm{KL}$ : Symptom overlap and comorbidity of irritable bowel syndrome with other conditions. Curr Gastroenterol Rep 2005, Aug:264-271.

29. Wise CM, Semble EL, Dalton CB: Musculoskeletal chest wall syndromes in patients with noncardiac chest pain: a study of 100 patients. Arch Phys Med Rehabil 1992, 73:147-149.

30. Fukui PT, Gonçalves TR, Strabelli CG, Lucchino NM, Matos FC, Santos JP, Zukerman E, Zukerman-Guendler V, Mercante JP, Masruha MR, Vieira DS, Peres MF: Trigger factors in migraine patients. Arq Neuropsiquiatr 2008, 66:494-499.

31. Wessely S, Nimnuan C, Sharpe M: Functional somatic syndromes: one or many? Lancet 1999, 354:936-939.

32. Fink $P$, Schröder A: One single diagnosis, bodily distress syndrome, succeeded to capture 10 diagnostic categories of functional somatic syndromes and somatoform disorders. J Psychosom Res 2010, 68:415-426.

Pre-publication history

The pre-publication history for this paper can be accessed here: http://www.biomedcentral.com/1471-2377/11/30/prepub

doi:10.1186/1471-2377-11-30

Cite this article as: Ravindran et al:: Migraine headaches in Chronic

Fatigue Syndrome (CFS): Comparison of two prospective cross-sectional studies. BMC Neurology 2011 11:30

\section{Submit your next manuscript to BioMed Central and take full advantage of:}

- Convenient online submission

- Thorough peer review

- No space constraints or color figure charges

- Immediate publication on acceptance

- Inclusion in PubMed, CAS, Scopus and Google Scholar

- Research which is freely available for redistribution

Submit your manuscript at www.biomedcentral.com/submit
Ciomed Central 